\title{
Analysis of Factors Influencing User Intention to Use Smart Health Care Services
}

\author{
Yoo-Jin Moon \\ Faculty of Global Business \& Technology, Hankuk University of Foreign Studies, Seoul, South Korea
}

Email address:

yjmoon@hufs.ac.kr

\section{To cite this article:}

Yoo-Jin Moon. Analysis of Factors Influencing User Intention to Use Smart Health Care Services. American Journal of Networks and Communications. Vol. 5, No. 4, 2016, pp. 68-72. doi: 10.11648/j.ajnc.20160504.11

Received: June 25, 2016; Accepted: July 7, 2016; Published: August 1, 2016

\begin{abstract}
This study analyzes factors influencing user intention to use various smart health care services on the empirical level. The analysis shows that users of smart health care services have higher degree of effort expectancy and intention to use the service than non-users. Also, the high potential usages of the service are more positively correlated with the health enhancement, the performance expectancy, the recommendations from friends or family, and the perceived enjoyment or attractiveness of the service than the convenience of usage, the device compatibility with smart devices, and the personal innovativeness.
\end{abstract}

Keywords: Smart Health Care, User Intention to Use, Personal Innovativeness, Effort Expectancy, Social Influence, Performance Expectancy, Perceived Enjoyment, Facilitating Conditions

\section{Introduction}

Recently, smart health care services are recognized as a new trend in mobile applications. With people demanding comparatively more health related services, smart health care services attract many people's attention. The aim of this study is to analyze factors influencing user intention to use various smart health care services on empirical level. The findings of this paper will redound to the benefit of companies considering performance expectancy in order to dominate smart health care service market, to quickly react to word of mouth, and to improve enjoyment and attractiveness of smart health care services.

And this paper first deals with introducing smart health care services and presenting theoretical background. Then it suggests the research model and hypotheses, conveys the results of hypotheses verification and empirical analysis, and provides some conclusions.

\section{Theoretical Background}

Smart health care means to diagnose and manage individuals' health condition by monitoring the amount of exercise, the blood sugar level, the electrocardiogram, and the heart rate etc. using mobile devices connected to health measurement devices or smartphone applications. For example, Smart Health Trainer lets one to check the amount and intensity of the exercise by using smartphone containing a sensor. Also, various health bands save and share data about the amount calories burnt, the psychological state, and distance traveled. Other examples include a smart pace counter, a smart drunkometer, a smart diet coach, a smart toothbrush, smart under-wears, a smart fork, a smart pill, smart contact lenses, and wearable smart skin patches $[1,2]$.

Smart health care service is within the advanced technology or new technology which is the subject of the information technology acceptance theory. Information technology acceptance theory is related to decision making of human's willingness to accept new technology. So technology advancement study includes variables related to human's attitude or intention. This study set the research model using UTAUT (Unified Theory of Acceptance and Use of Technology) which integrates the existed theories.

UTAUT proposed by [3] includes three variables (performance expectancy, effort expectancy, and social influence) that affect intention to use, one variable (facilitating conditions) that affects usage behavior, and four controlled variables (sex, age, experience, and voluntariness) [3]. This study includes exogenous variables, such as 
personal innovativeness and perceived enjoyment, which seem crucial when applying smart health care service technology to UTAUT.

\section{Research Model and Hypothesis}

\subsection{Sample}

To define the demographics of respondents, a frequency analysis and descriptive statistics analysis was performed on a total of 126 samples. We used a non-probability sampling. Those questioned completed self-reported questionnaires and voluntarily participated in responding the questionnaires. Male is $67.5 \%$ and female $32.5 \%$, and the experienced $23.8 \%$ and non-users $76.2 \%$.

\subsection{Research Model}

This study extracted variables such as effort expectancy, social influence, performance expectancy, facilitating conditions proposed by [3, 4] as important factors affecting intention to use smart health care service. Also, this study added additional variables personal innovativeness and perceived enjoyment proposed by $[5,6]$ using Davis' TAM (Technology Acceptance Model). This research model is depicted in Figure 1.

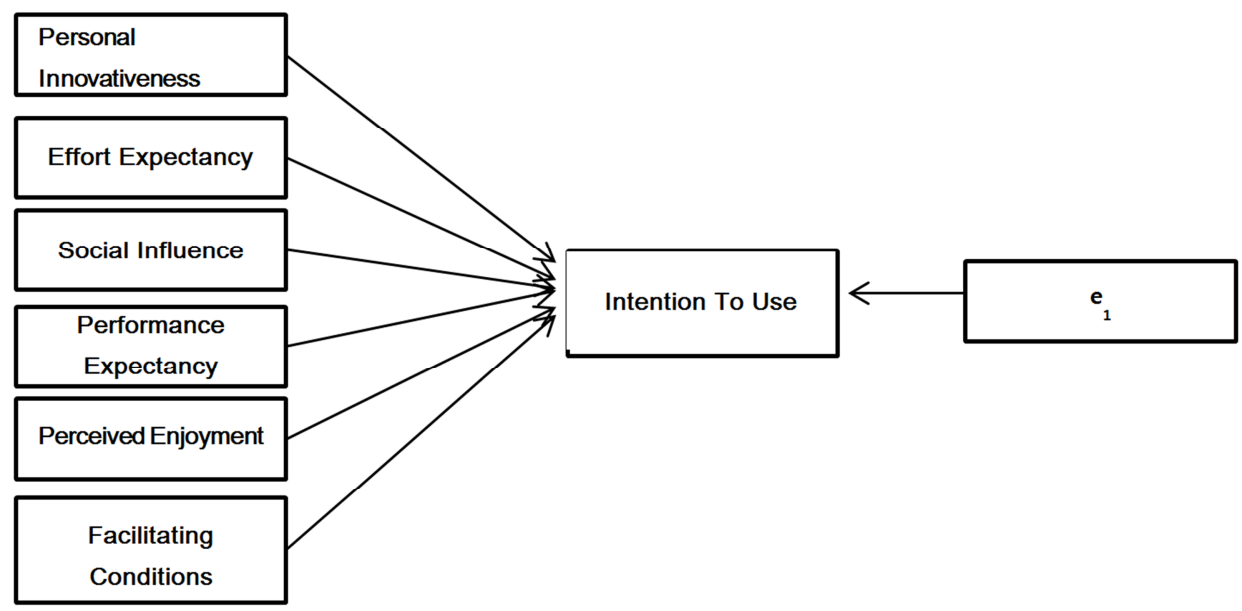

Figure 1. Research Model.

\subsection{Hypothesis Setting}

\subsubsection{Demographic Variables}

Hypothesis 1-1: Gender differences in personal innovativeness, effort expectancy, social influence, performance expectancy, perceived enjoyment, facilitating conditions, intention to use would exist.

Hypothesis 1-2: Differences in service experience would show different levels of personal innovativeness, effort expectancy, social influence, performance expectancy, perceived enjoyment, facilitating conditions, intention to use.

\subsubsection{UTAUT Variables}

Hypothesis 2-1: Effort expectancy would have positive impact on user intention to use smart health care service.

Hypothesis 2-2: Social influence would have positive impact on user intention to use smart health care service.

Hypothesis 2-3: Performance expectancy would have positive impact on user intention to use smart health care service.

Hypothesis 2-4: Facilitating conditions would have positive impact on user intention to use smart health care service.

\subsubsection{Additional Variables}

Hypothesis 3-1: Personal innovativeness would have positive impact on user intention to use smart health care service.

Hypothesis 3-2: Perceived enjoyment would have positive impact on user intention to use smart health care service.

\section{Hypothesis Verification and Empirical Analysis}

\subsection{Verification of Research Model}

This study verified reliability and validity of the model using collected data $(n=126)$.

\subsubsection{Reliability Analysis}

This study analyzed and tested reliability between multiitem scales on 22 measurement variables using SPSS 18 statistics program. Table 1 showed that all Cronbach $\alpha$ coefficients were above 0.7 and the reliability was secured.

Table 1. The Analysis Result of Reliability.

\begin{tabular}{llll}
\hline Variables & $\begin{array}{l}\text { No. of } \\
\text { Items }\end{array}$ & $\begin{array}{l}\text { Cronbach } \\
\boldsymbol{\alpha}\end{array}$ & $\begin{array}{l}\text { Standardized } \\
\text { Cronbach } \boldsymbol{\alpha}\end{array}$ \\
\hline Personal Innovativeness & 4 & .901 & .902 \\
Effort Expectancy & 3 & .872 & .873 \\
Social Influence & 3 & .868 & .869 \\
Performance Expectancy & 3 & .873 & .873 \\
Perceived Enjoyment & 3 & .870 & .870 \\
Facilitating Conditions & 3 & .884 & .885 \\
Intention to Use & 3 & .868 & .869 \\
\hline
\end{tabular}




\subsubsection{Validity Analysis}

The study performed the exploratory factor analysis about items of questionnaire measuring constructs of research model. Factor extraction method is based on principal component analysis and Varimax rotation with Kaiser normalization $[7,8]$.

The result of factor analysis showed that all seven initially intended factors including the dependent variable were extracted. In order words, factor 1 was named personal innovativeness, factor 2 perceived enjoyment, factor 3 social influence, factor 4 performance expectancy, factor 5 intention to use, factor 6 facilitating conditions, factor 7 effort expectancy. Each factor showed that Eigen value is above 1 and the rate of cumulative variance showed $82.8 \%$ of total variance. We found that multi-collinearity did not exist. Table 2 showed the results of exploratory factor analysis.

Table 2. Results of Exploratory Factor Analysis.

\begin{tabular}{|c|c|c|c|c|c|c|c|c|}
\hline Factors & Item & Factor 1 & Factor 2 & Factor 3 & Factor 4 & Factor 5 & Factor 6 & Factor 7 \\
\hline \multirow{4}{*}{ Personal Innovativeness } & V1 & .833 & .261 & .081 & .155 & .001 & .134 & .002 \\
\hline & $\mathrm{V} 2$ & .894 & .012 & .128 & .137 & .119 & .017 & .060 \\
\hline & V3 & .781 & .050 & .104 & .045 & .266 & .032 & .261 \\
\hline & V4 & .767 & .166 & .101 & .055 & .042 & .168 & .348 \\
\hline \multirow{3}{*}{ Effort Expectancy } & V5 & .257 & .214 & .109 & .240 & .095 & .218 & .721 \\
\hline & V6 & .218 & .082 & .238 & .161 & .266 & .198 & .691 \\
\hline & V7 & .190 & .389 & .271 & .226 & .111 & .115 & .716 \\
\hline \multirow{3}{*}{ Social Influence } & V8 & .182 & .240 & .743 & .180 & .278 & .246 & .211 \\
\hline & V9 & .160 & .276 & .819 & .205 & .191 & .183 & .168 \\
\hline & V10 & .143 & .261 & .783 & .242 & .186 & .215 & .215 \\
\hline \multirow{3}{*}{ Performance Expectancy } & V11 & .063 & .178 & .273 & .770 & .296 & .170 & .164 \\
\hline & V12 & .110 & .269 & .208 & .648 & .216 & .209 & .327 \\
\hline & V13 & .157 & .233 & .151 & .828 & .202 & .193 & .178 \\
\hline \multirow{3}{*}{ Perceived Enjoyment } & V14 & .098 & .675 & .250 & .215 & .200 & .149 & .224 \\
\hline & V15 & .103 & .794 & .259 & .179 & .339 & .107 & .202 \\
\hline & V16 & .187 & .756 & .264 & .286 & .248 & .155 & .177 \\
\hline \multirow{3}{*}{ Facilitating Conditions } & V17 & .185 & .075 & .235 & .103 & .052 & .847 & .156 \\
\hline & V18 & .032 & .340 & .276 & .280 & .100 & .692 & .095 \\
\hline & V19 & .075 & .051 & .066 & .164 & .335 & .778 & .206 \\
\hline \multirow{3}{*}{ Intention to Use } & V20 & .193 & .295 & .202 & .387 & .710 & .186 & .109 \\
\hline & V21 & .145 & .323 & .262 & .242 & .783 & .208 & .216 \\
\hline & V22 & .164 & .257 & .230 & .219 & .770 & .171 & .162 \\
\hline Eigen Value & & 6.61 & 4.89 & 5.04 & 4.30 & 4.91 & 5.10 & 3.99 \\
\hline Explained Variance (\%) & & 15.711 & 11.620 & 11.968 & 10.224 & 11.661 & 12.115 & 9.476 \\
\hline KMO & & .828 & & & & & & \\
\hline
\end{tabular}

\subsection{Hypothesis Verification}

\subsubsection{T-test Verification Regarding Gender and User Experience}

The result of T-test verification on independent sample showed that no statistically significant difference between genders existed so we rejected hypothesis 1-1. We partially accepted hypothesis 1-2 because effort expectancy and intention to use showed statistically significant differences at the level of $\alpha=.05$ according to user experience. Table 3 showed that the results of T-test on gender differences and Table 4 showed that the results of T-test on experience differences.

Table 3. Results of T-test between Genders.

\begin{tabular}{|c|c|c|c|c|}
\hline & \multicolumn{2}{|c|}{ Levine's Equal Variance Test } & \multicolumn{2}{|c|}{ T-test on Identity of Mean } \\
\hline & $\mathbf{F}$ & $\alpha$ & $\mathbf{t}$ & $\alpha$ (two-tail) \\
\hline Personal Innovativeness & 4.508 & .036 & 1.043 & .299 \\
\hline Effort Expectancy & .330 & .567 & .780 & .437 \\
\hline Social Influence & 6.772 & .011 & -1.317 & .190 \\
\hline Performance Expectancy & 2.457 & .120 & -.292 & .771 \\
\hline Facilitating Conditions & 1.972 & .163 & -.020 & .984 \\
\hline Intention to Use & 5.935 & .016 & -1.015 & .312 \\
\hline
\end{tabular}


Table 4. Results of T-test between Experienced Users and Non-Users.

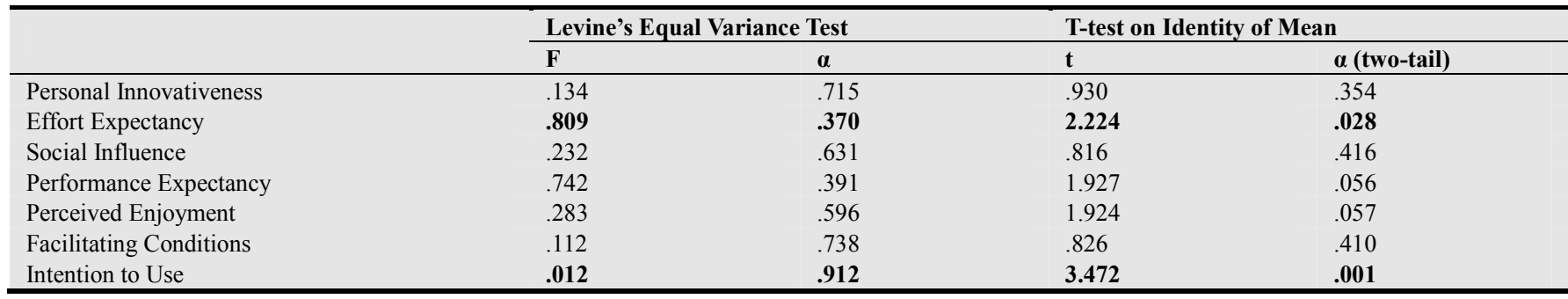

\subsubsection{Hypothesis Verification Using Multiple Regression Analysis}

This study used multiple regression analysis by setting intention to use smart health care service as a dependent variable and other six variables (personal innovativeness, performance expectancy, social influence, performance expectancy, perceived enjoyment, facilitating conditions) as independent variables. The results of multiple regression analysis showed that three of the six hypotheses suggested turned out statistically significant. Table 5 showed the results of multiple regression analysis.

Table 5. Results of Multiple Regression Analysis.

\begin{tabular}{|c|c|c|c|c|c|c|c|}
\hline Dependent Variable & Independent Variables & B & Standard Error & B & $\mathbf{t}$ & $\boldsymbol{\alpha}$ & Acc./Rej. \\
\hline \multirow{7}{*}{ Intention to Use } & Constant & -.81 & .397 & & -2.042 & .043 & \\
\hline & Personal Innovativeness & .089 & .071 & .084 & 1.253 & .213 & Reject \\
\hline & Effort Expectancy & .042 & .101 & .036 & .417 & .677 & Reject \\
\hline & Social Influence & .172 & .091 & .167 & 1.911 & .050 & Accept \\
\hline & Performance Expectancy & .343 & .101 & .289 & 3.412 & .001 & Accept. \\
\hline & Perceived Enjoyment & .319 & .098 & .288 & 3.266 & .001 & Accept \\
\hline & Facilitating Conditions & .098 & .077 & .094 & 1.268 & .207 & Reject \\
\hline$R^{2}: .614$ & & & & & & & \\
\hline F-value: 31.579 & & & & & & & \\
\hline
\end{tabular}

Hypothesis 2-1 was dismissed because it indicated that effort expectancy did not have a statistical significance on intention to use smart health care service at the $\alpha=.05$ and $\beta=.036, \mathrm{t}=.417$. This result did not support the preexisting studies $[3,4,6,9]$; it indicated that ease of use, ease of acquiring results and usefulness had nothing to do with user intention to use. Hypothesis 2-2 was accepted because it showed that social influence did have a statistical significance on user intention to use smart health care service at the $\alpha=.05$ and $\beta=.167, t=1.911$. This result did support the preexisting studies $[3,5,9]$; it indicated that user intention to use smart health care service was positively affected by recognition of surrounding people, influential people, and important people who believed that I should use smart health care service.

Hypothesis 2-3 was accepted because it showed that performance expectancy did have a statistical significance on user intention to use smart health care service at the $\alpha=.05$, $\beta=.289$, and $\mathrm{t}=3.412$. This result did support the preexisting studies $[3,4,9,10]$; it indicated that user intention to use smart health care service was positively affected by helping health enhancement, time saving, health condition improvement through the smart health care service. Hypothesis 2-4 was dismissed because it showed that facilitating conditions did not have a statistical significance on user intention to use smart health care service at the $\alpha=.05$, $\beta=.094$, and $t=1.268$. This result did not support the preexisting studies $[3,8,9]$; it indicated that quick afterservice support, compatibility with smart-phones, and advice from experts had nothing to do with service usage intention.

Hypothesis 2-5 was dismissed because it showed that personal innovativeness did not have a statistical significance on user intention to use smart health care service at the $\alpha=.05$, $\beta=.084$, and $t=1.253$. This result did not support the preexisting studies $[3,10,11,12]$; it indicated that tendency of personal innovativeness had nothing to do with user intention to use. Hypothesis 2-6 was accepted because it showed that perceived enjoyment did have a statistical significance on user intention to use smart health care service at the $\alpha=.05, \beta=.288$, and $t=3.266$. This result did support the preexisting studies $[3,10,11,13]$; it indicated that enjoyment attractiveness and interest of smart health care service had positive effect on user intention to use.

\section{Conclusion}

This study was conducted to analyze and verify how factors affect users' intention to use smart health care service by surveying college student who may potentially use these services.

The results of T-test verification and multiple regression analysis are as follows. First, T-test verification between gender differences did not show a statistically significant difference on seven variables. Second, experienced smart health care service did show a statistically significant difference on effort expectancy and user intention to use. Third, effort expectancy did not show a statistically significant difference on user intention to use smart health care services. Fourth, social influence did show a statistically significant difference on user intention to use smart health care services. Fifth, performance expectancy did show a statistically significant difference on user intention to use 
smart health care services. Sixth, facilitating conditions did not show a statistically significant difference on user intention to use smart health care services. Seventh, personal innovativeness did not show a statistically significant difference on user intention to use smart health care services. Eighth, perceived enjoyment did show a statistically significant difference on user intention to use smart health care services.

These results imply that the usage of smart health care services are more influenced by health enhancement, recommendation from family and colleague, perceived enjoyment than ease of use, compatibility, innovative tendency do.

These results indicate that in order to dominate smart health care service market, companies need to increase performance expectancy, quickly react to word of mouth, and improve enjoyment and attractiveness of smart health care service.

\section{Acknowledgements}

This work was supported by Hankuk University of Foreign Studies Research Fund of 2015.

\section{References}

[1] Peck, J. L., Stanton, M., and Reynolds, G. E., "Smartphone Preventive Health Care: Parental Use of Immunization Reminder System," Journal of Pediatric Health Care, 28 (1), pp. 35-42, 2014.

[2] Bag, J., Roy, S, and Sarkar Sr., S. K., "FPGA Implementation of Advanced Health Care System Using Zig-Bee Enabled RFID Technology,"2014 IEEE International Advance Computing Conference (IACC), pp. 899-904, 2014.

[3] Venkatesh, V., Morris, M., Davis, G., and Davis, F., "User Acceptance of Information Technology: Toward a Unified View,” MIS Quarterly, 27 (3), pp. 425-478, 2003.
[4] Parameswaran, S., Kishore, R., and Li, P., "Within-Study Measurement Invariance of the UTAUT Instrument: An Assessment with User Technology Engagement Variables," Information \& Management, 52 (3), pp. 317-336, 2015.

[5] Agarwal, R. and Karahanna, E., "Time Flies When You're Having Fun: Cognitive Absorption and Beliefs about Information Technology Usage," MIS Quarterly, 24 (4), pp. 665-694, 2000.

[6] Wallace, L. G. and Sheetz, S. D., "The Adoption of Software Measures: A Technology Acceptance Model (TAM) Perspective," Information \& Management, 51, pp. 249-259, 2014.

[7] Aizstrauta, D., Ginters, E., and Eroles, M. P., "Applying Theory of Diffusion of Innovations to Evaluate Technology Acceptance and Sustainability," Procedia Computer Science, 43, pp. 69-77, 2015.

[8] Hwang, Y., Hwang, W., and Moon, Y., “A Study of Factors Influencing Intra-Organizational Potential Users' Intention to Use N-screen Service," Korean Comparative Government Review, 16 (1), pp. 89-114, 2012.

[9] Lescevica, M., Ginters, E., and Mazza, R., "Unified Theory of Acceptance and Use of Technology (UTAUT) for Market Analysis FP 7 CHOReOS Products," Procedia Computer Science, 26, pp. 51-68, 2013.

[10] Sternad, S. and Bobek, S., "Impacts of TAM-based External Factors on ERP Acceptance", Procedia Technology, 9, pp. 3343, 2013.

[11] Jung, C. and Namn, S., "Cloud Computing Acceptance at Individual Level Based on Extended UTAUT," Journal of Digital Convergence, 12 (1), pp. 287-294, 2014.

[12] Escobar-Rodríguez, T. and Carvajal-Trujillo, E., "Online Purchasing Tickets for Low Cost Carriers: An Application of the Unified Theory of Acceptance and Use of Technology (UTAUT) Model," Tourism Management, 43, pp. 70-88, 2014.

[13] Oliveira, T., Faria, M., Thomas, M. A., and Popovič, A., "Extending the Understanding of Mobile Banking Adoption: When UTAUT Meets TTF and ITM," International Journal of Information Management, 34 (5), pp. 689-703, 2014. 